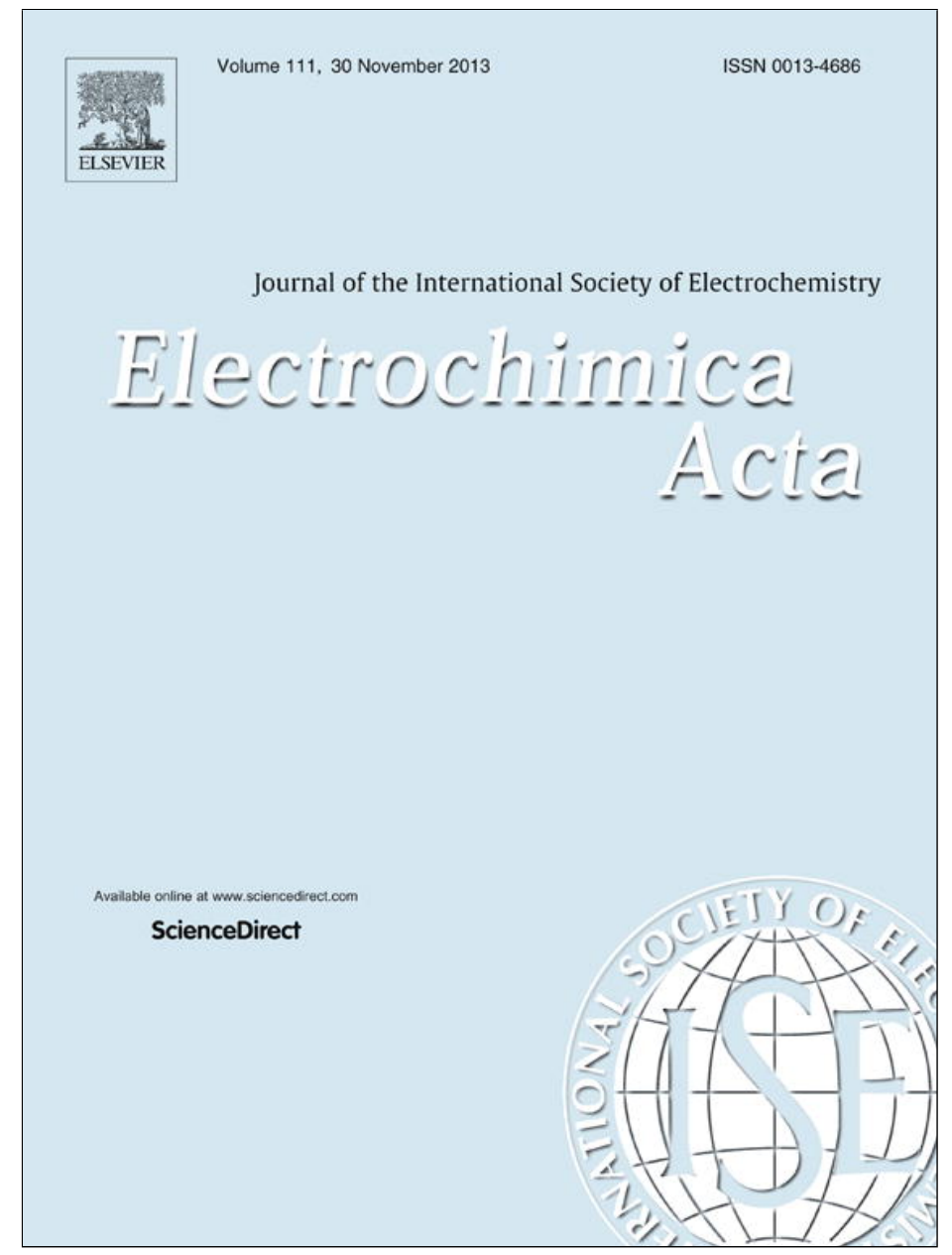

This article appeared in a journal published by Elsevier. The attached copy is furnished to the author for internal non-commercial research and education use, including for instruction at the authors institution and sharing with colleagues.

Other uses, including reproduction and distribution, or selling or licensing copies, or posting to personal, institutional or third party websites are prohibited.

In most cases authors are permitted to post their version of the article (e.g. in Word or Tex form) to their personal website or institutional repository. Authors requiring further information regarding Elsevier's archiving and manuscript policies are encouraged to visit:

http://www.elsevier.com/authorsrights 


\title{
Preparation of nanoporous carbon microspheres by subcritical water carbonization and electrocapacitive study
}

\author{
Alfin Kurniawan ${ }^{\mathrm{a}, 1}$, Chintya Effendi ${ }^{\mathrm{a}, 1}$, L.K. Ong ${ }^{\mathrm{a}, 1}$, Fredi Kurniawan ${ }^{\mathrm{a}, 1}$, C.X. Lin ${ }^{\mathrm{b}}$, \\ Artik Elisa Angkawijaya ${ }^{c}$, Yi-Hsu Ju $^{c}$, Suryadi Ismadji ${ }^{\mathrm{a}, *}$, X.S. Zhao ${ }^{\mathrm{b}, * *}$ \\ a Department of Chemical Engineering, Widya Mandala Surabaya Catholic University, Kalijudan 37, Surabaya 60114, Indonesia \\ ${ }^{\mathrm{b}}$ School of Chemical Engineering, The University of Queensland, St. Lucia, Brisbane, QLD 4072, Australia \\ ${ }^{c}$ Department of Chemical Engineering, National Taiwan University of Science and Technology, No. 43, Sec. 4, Keelung Rd., Taipei 106, Taiwan
}

\section{A R T I C L E I N F O}

\section{Article history:}

Received 19 July 2013

Accepted 30 July 2013

Available online 14 August 2013

\section{Keywords:}

Sugar

Nanoporous carbon microspheres

Subcritical water carbonization

Microwave activation

Capacitance

\begin{abstract}
A B S T R A C T
In this work, sugar-derived carbon microspheres (CMSs) with diameters in the range of $5-10 \mu \mathrm{m}$ and uniform nanopores were prepared using the subcritical water carbonization method, followed by microwave-assisted $\mathrm{KOH}$ activation. The carbonization was conducted at $3 \mathrm{MPa}$ and moderate temperatures $\left(150-170^{\circ} \mathrm{C}\right)$ in subcritical water, which is a green dehydrating agent. The formation of the CMSs from a sugar solution under subcritical water conditions followed a radical-catalysed emulsion polymerization mechanism. The specific surface area and pore volume of the CMSs were found to increase with increasing the mass ratio of $\mathrm{KOH}$ over carbon up to 1:1. Electrocapacitive results showed that a sample prepared at a $\mathrm{KOH}$ to carbon ratio of $1: 1$ and microwave irradiation level of $70 \%$ possessed the highest specific capacitance (about $179.2 \mathrm{~F} / \mathrm{g}$ ) at a current density of $1 \mathrm{~A} / \mathrm{g}$ and excellent cycling performance over 1000 charging/discharging cycles without significantly loss in capacitance. The specific capacitance and capacitive retention of this electrode are comparable to that of an electrode prepared from commercial YP-80F activated carbon.
\end{abstract}

(c) 2013 Elsevier Ltd. All rights reserved.

\section{Introduction}

Supercapacitors, also known as electric double-layer capacitors (EDLCs) or ultracapacitors are an advanced energy storage device that store and release energy as charge. Supercapacitors are superior to other electrochemical energy storage devices available today in terms of power density. Another unique feature of this energy storage device is its virtually an unlimited number of cycle life [1]. Unlike electrolytic capacitors, supercapacitors do not have conventional solid dielectric to separate the electrodes but an extremely thin physical porous layer. Current research has been prioritized for designing porous carbon materials with well-defined properties, such as high specific surface area and appropriate pore size and hierarchy for rapid ion transport [2].

Amongst porous carbons, activated carbon is the most popularly used electrode for supercapacitors owing to its high surface area, tunable pore structure, excellent mechanical and chemical stabilities, low cost and ready availability [3-5]. In this context,

\footnotetext{
* Corresponding author. Tel.: +62 31389 1264; fax: +62 313891267.

** Corresponding author. Tel.: +61 73346 9997; fax: +61 733654199.

E-mail addresses: suryadiismadji@yahoo.com, alfin_kur@yahoo.com (S. Ismadji), george.zhao@uq.edu.au (X.S. Zhao).

1 These authors contributed equally to this work
}

the specific surface area and pore size play key roles in determining the electrocapacitive properties [6-10]. Rufford and co-workers developed a nanoporous carbon from waste coffee beans with pore sizes ranging from less than $1 \mathrm{~nm}$ (narrow micropores) to $4 \mathrm{~nm}$ (mesopores) [8]. The materials displayed an extraordinarily high capacitance $(368 \mathrm{~F} / \mathrm{g})$ at a current density of $0.05 \mathrm{~A} / \mathrm{g}$ in two-electrode cell and an excellent stability after 10,000 chargedischarge cycles [8]. An attempt was made by Ismanto et al. for the preparation of activated carbon derived from agricultural waste (i.e., cassava peel) through $\mathrm{KOH}$-chemical activation and $\mathrm{CO}_{2}$ physical activation approaches [10]. The material was used as an electrode to configure a supercapacitor device, which displayed a capacitance of $153 \mathrm{~F} / \mathrm{g}$ [10]. Recently, sugars (e.g., xylose, fructose, glucose, and sucrose) have been utilized as a carbon precursor to synthesize porous carbon materials via activation [6,11-13], template [14-16], and hydrothermal methods $[5,17,18]$. There are several advantages of employing sugars as a carbon precursor, such as low cost, ready availability, high purity, and the existence of aromatic rings required to form graphitic carbon. The carbons prepared using sugars have been found to possess spherical morphology in general, good thermal stability, and excellent electric conductivity [5,17].

Carbon micro/nanospheres (CMSs/CNSs) have found applications as Li-ion battery anode [19-21], biosensor electrodes for sensing heavy metal ions [22], catalyst supports [23-25], and 
electrode materials for supercapacitors [5,26]. Nevertheless, for the latest application, a green and facile route to prepare these carbon materials with suitable packing structure and pore network is still challenging. In this work, we succeeded in synthesizing sugarderived nanoporous CMSs using a catalyst-free carbonization method under subcritical water conditions. In this method, subcritical water (or hot compressed water) acts as a dehydrating agent and a reaction medium to convert sugar into carbon. Therefore, the subcritical water carbonization technique is considered more environmentally friendly for preparing carbon microspheres than other methods, such as the template [27,28], pyrolysis [29-31], reduction $[32,33]$ and chemical vapor deposition method [34]. Microwaveassisted $\mathrm{KOH}$ activation was conducted to improve the porosity of the carbon. The carbon microspheres before and after $\mathrm{KOH}$ activation were tested in a two-electrode supercapacitor using cyclic voltammetry (CV) and galvanostatic charge-discharge techniques.

\section{Experimental}

\subsection{Chemicals}

Commercial sugar as a carbon precursor was obtained from a local supermarket in Surabaya, East Java, Indonesia. Analyticalgrade PTFE (polytetrafluoroethylene) latex (60 wt\% dispersion in $\mathrm{H}_{2} \mathrm{O}$ ) and potassium hydroxide $(\mathrm{KOH})$ were supplied by Sigma Aldrich, Singapore and used without further purification. Nickel foam substrate $(99.9 \%, 30 \mathrm{~cm}$ in length $\times 8 \mathrm{~cm}$ in width $\times 80 \mu \mathrm{m}$ in thickness) and Vulcan XC-72 carbon black were purchased from MTI Corp. and Cabot Corp., respectively. Distilled water was used throughout all experiments.

\subsection{Synthesis of carbon microspheres from sucrose solution}

The subcritical water carbonization experiment was performed in a high-pressure batch reactor. All fittings and tubings and the reactor itself were made of 316SS-grade stainless steel. The pressure in the reactor was generated using highly pure nitrogen (99.98\%). Sugar solutions were prepared by dissolving a given amount of sugar in deionized water to give sugar/water mass ratios of $1: 1(50 \%), 2: 3(40 \%)$ and $1: 2(33 \%)$, respectively. A sugar solution was vigorously stirred magnetically at $500 \mathrm{rpm}$ for $1 \mathrm{~min}$ before putting into the reactor. The system was purged with nitrogen to remove air. Subsequently, the reactor was heated from room temperature to a desired temperature $(423 \mathrm{~K}, 433 \mathrm{~K}$, and $443 \mathrm{~K})$ at $30^{\circ} \mathrm{C} /$ min while keeping the internal pressure at $3 \mathrm{MPa}$. The carbonization was conducted isothermally and isobarically. After a given period of time $(6 \mathrm{~h}, 8 \mathrm{~h}$, and $10 \mathrm{~h})$, the reactor was cooled down to room temperature. The solid carbon was separated, washed with distilled water and subsequently dried in an oven at $383 \mathrm{~K}$ for $24 \mathrm{~h}$. Here, the sample collected is designated as P-CMS- $X-Y-Z$ where $X$, $Y$, and $Z$ refer to the concentration of sugar in the solution (wt\%), carbonization temperature and carbonization time, respectively. For example, sample P-CMS-50-433-8 was prepared from 50 wt\% sugar solution at $433 \mathrm{~K}$ for $8 \mathrm{~h}$. The yield of the carbon products was calculated using the following equation:

Yield $(\%)=\left(\frac{m_{1}}{m_{2}}\right) \times 100 \%$

where $m_{1}$ and $m_{2}$ are the mass of carbon obtained ( $\mathrm{g}$ ) and mass of sugar used $(\mathrm{g})$, respectively.

\subsection{Microwave-assisted chemical activation of P-CMS}

Microwave activation is now becoming a highlighted technique for the surface modification of carbon-based materials. The principle of this technique is based on the conversion of electrical energy to microwave energy that is used for the vibration and molecular evaporation of trapped polar groups from the carbon walls [35], leaving open spaces responsible for higher surface area and porosity. This technique has proven superior to conventional thermal activation method in terms of time- and energy-saving and greater efficiency in intermittent use. The chemical activation of the P-CMS samples was conducted by soaking $10 \mathrm{~g}$ of the solid carbon into a given volume of a $50 \mathrm{wt} \% \mathrm{KOH}$ solution to give a mass ratio of KOH over carbon of $1: 2,1: 1,3: 2$ and $2: 1$. The mixture was then allowed to stand for $24 \mathrm{~h}$ under vigorous stirring by a magnetic stirrer at $500 \mathrm{rpm}$ to ensure good penetration of the activating chemical into the carbon matrix. The impregnated carbon was washed several times with deionized water to remove superficial $\mathrm{KOH}$ and centrifuged at $4000 \mathrm{rpm}$ for $10 \mathrm{~min}$ to remove liquid fraction. The solid fraction was collected and oven-dried at $383 \mathrm{~K}$ for $2 \mathrm{~h}$. Subsequently, the solid was placed in a microwave oven (Inextron, the maximum irradiation power is $900 \mathrm{~W}$ ) and irradiated at various levels of $50 \%(450 \mathrm{~W}), 60 \%$ ( $540 \mathrm{~W}), 70 \%(630 \mathrm{~W}$ ) and 80\% (720 W) with a frequency of $2.45 \mathrm{GHz}$ for $10 \mathrm{~min}$. Nitrogen was introduced at a flow rate of $50 \mathrm{ml} / \mathrm{min}$ during heating and cooling. The resultant solids were rinsed sequentially with $0.1 \mathrm{M} \mathrm{HCl}$ and distilled water until the $\mathrm{pH}$ of the washing solution was in the range of 6-7. The products were dried in an oven at $383 \mathrm{~K}$ for $24 \mathrm{~h}$ and sieved. The $\mathrm{KOH}$-activated carbon microsphere samples are designated as M-CMS- $m-n$ where $m$ and $n$ refer to $\mathrm{KOH} /$ carbon mass ratio and microwave irradiation level (\%), respectively.

\subsection{Characterizations of P-CMS and M-CMS samples}

$\mathrm{N}_{2}$ sorption measurements were conducted on an automated Micromeritics ASAP 2010 sorption analyzer at 77 K. Prior to analysis, the samples were vacuum-degassed at $573 \mathrm{~K}$ and $10^{-3}$ Torr for $6 \mathrm{~h}$. The specific surface area was calculated by means of the Brunauer-Emmett-Teller (BET) method while microporous surface area $\left(S_{\text {mic }}\right)$ and micropore volume $\left(V_{\text {mic }}\right)$ were obtained from the Dubinin-Asthakov (DA) method. The total pore volume $\left(V_{\mathrm{T}}\right)$ was estimated from the volume of $\mathrm{N}_{2}$ adsorbed at a relative pressure of 0.995 . The pore size distribution (PSD) curves were deduced from the adsorption branches of the isotherms based on the Barrett-Joyner-Halenda (BJH) model.

The morphology of the samples was observed on a JEOL JSM6390 field emission scanning electron microscope equipped with a backscattered electron (BSE) detector at an accelerating voltage of $20 \mathrm{kV}$ and working distance of $12 \mathrm{~mm}$. The powder X-ray diffraction (XRD) patterns were acquired on a Philips X'pert X-ray diffractometer operating at $40 \mathrm{kV}$ and $30 \mathrm{~mA}$ using Ni-filtered $\mathrm{Cu} K \alpha_{1}$ $(\lambda=0.15405 \mathrm{~nm})$ as the radiation source with a scanning rate of $0.02^{\circ} / \mathrm{min}$ from 2 -theta angle of $5-70^{\circ}$. Raman scattering measurements were performed on a Renishaw Raman microspectrometer using an $\mathrm{Ar}^{+}$ion laser excitation wavelength at $514.5 \mathrm{~nm}(2.41 \mathrm{eV})$ in the frequency range of $200-2400 \mathrm{~cm}^{-1}$. The elemental carbon analysis was conducted on a PANalytical MiniPal QC energy dispersive X-ray fluorescence (EDXRF) spectrometer. FTIR spectra were collected from a Shimadzu FTIR 8400 s spectrophotometer using the $\mathrm{KBr}$ method.

\subsection{Preparation of working electrodes}

A working electrode was prepared from carbon slurry consisting of $90 \mathrm{wt} \%$ active material, $5 \mathrm{wt} \%$ carbon black, and $5 \mathrm{wt} \%$ PTFE. The mixture underwent ultrasonication treatment for $24 \mathrm{~h}$ at room temperature. The well-mixed slurry was then painted on a nickel foam strip, pressed at $15 \mathrm{MPa}$, and vacuum-dried at $383 \mathrm{~K}$ in a Lab-Line Duo-Vac oven. The typical mass load of the active material in an electrode was about $1 \mathrm{mg} / \mathrm{cm}^{2}$. A thin sheet of glassy fiber paper was used as the separator to prevent electric current 


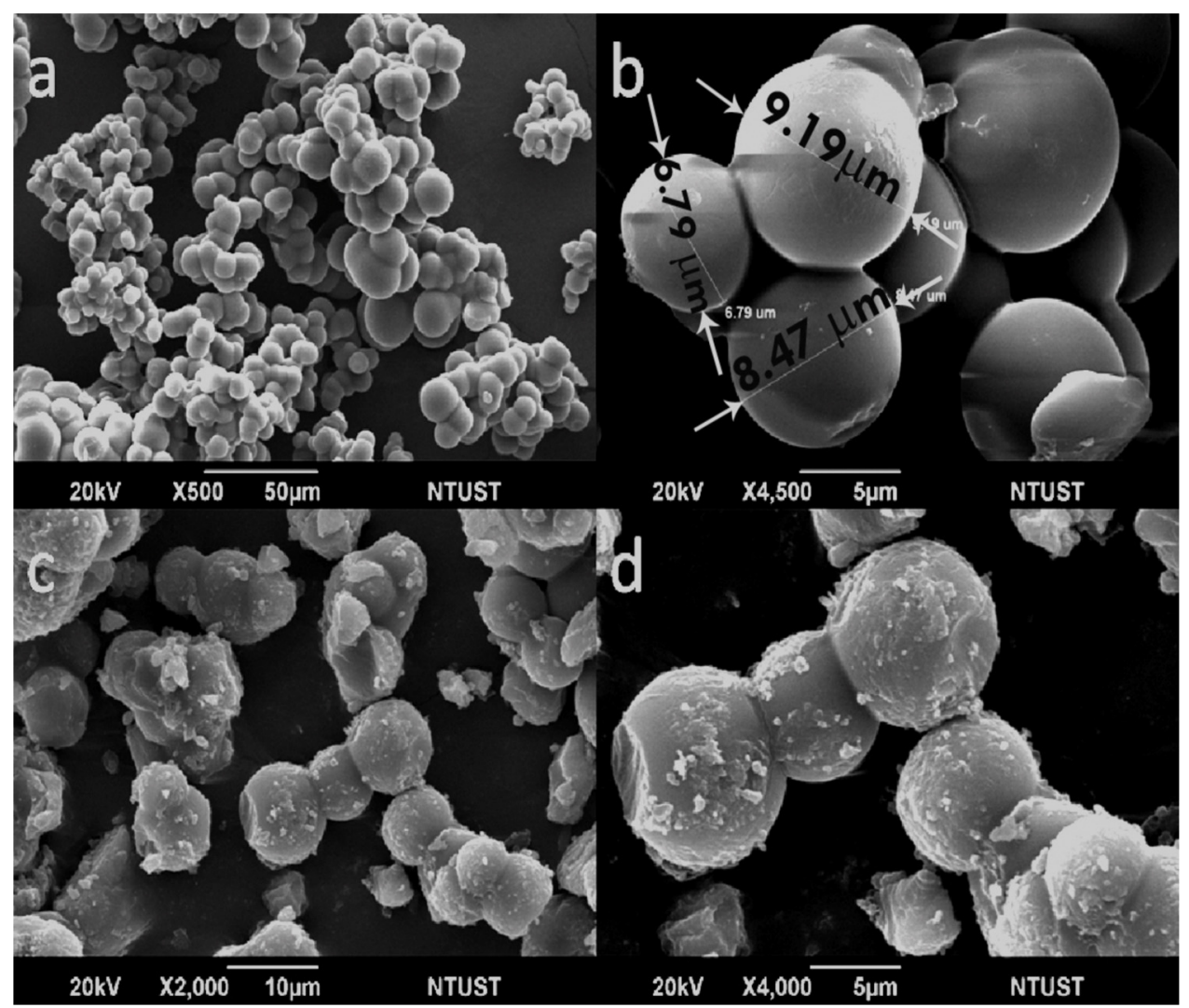

Fig. 1. SEM images of samples P-CMS-50-433-8 (a-b) and M-CMS-0.5-60 (c-d).

bridging between the anode and cathode. Prior to electrochemical tests, the electrodes were vacuum-impregnated with $30 \mathrm{wt} \% \mathrm{KOH}$ solution as the electrolytic fluid to guarantee thorough wetting. The as-prepared electrode with P-CMS as the active material was used as a benchmark of capacitance. For comparison, the electrocapacitive properties of a commercial activated carbon (YP-80F) that is a trademark of Kuraray Chemical Co. were also tested.

\subsection{Electrochemical measurements}

The electrochemical performance of the electrodes was tested by using cyclic voltammetry (CV) at a sweep rate of $50 \mathrm{mV} / \mathrm{s}$ in the potential window of $0-1 \mathrm{~V}$ and galvanostatic charge-discharge on a $\mathrm{CHI} 660 \mathrm{D}$ electrochemical workstation at room temperature. Three-electrode cell configuration was used as the electrochemical testing system, which consisted of a $1 \mathrm{~cm}^{2}$ platinum sheet as the counter electrode and $\mathrm{a} \mathrm{Hg} / \mathrm{HgO}$ as the reference electrode. The gravimetric specific capacitance of the electrodes $(C)$, in the unit of $\mathrm{F} / \mathrm{g}$, was determined from the charge/discharge curve according to the following equation $[6,13]$ :

$C=\frac{I \times \Delta t}{\Delta V \times m}$

where $I$ is the discharge current (A), $\Delta t$ is the discharge time (s), $\Delta V$ is the potential change during discharge $(\mathrm{V})$, and $m$ is the mass of the active material in an electrode $(\mathrm{g})$. All potential measurements were specified relative to $\mathrm{Hg} / \mathrm{HgO}$ reference electrode.

\section{Results and discussion}

\subsection{Morphology and pore structure of P-CMS and M-CMS}

Fig. 1a-d show the SEM images of the carbon microspheres before and after $\mathrm{KOH}$ activation. It is clearly seen that the materials exhibit an intertwined structure, resembling an alveoli-like shape with a good sphericity and smooth surface. The diameter of the P-CMS samples ranges between $5 \mu \mathrm{m}$ and $10 \mu \mathrm{m}$, as is seen from Fig. 1b. A recent paper of Ryu et al. also described carbon microspheres prepared from fructose solution with an intertwined morphology [18]. The morphology of sample M-CMS-0.5-60 inherited an intertwined structure as is seen from Fig. 1c and d. The average particle size of the carbon spheres obtained in this work is comparable to that of Wang et al. [17] and Ryu et al. [18] (in the micron scale) but 50 to a 100 times larger than that obtained by Yuan et al. [5] (in the nanoscale). In their studies, Wang et al. and Yuan et al. hydrothermally treated a sucrose solution to prepare carbon micro- and nanospheres while Ryu et al. used a mixture of monosaccharide-phenol derivative compounds for synthesizing micron-size carbon spheres using the same approach.

Table 1 lists the characteristics of P-CMS samples. It can be seen that the carbonization time, temperature, and concentration of sugar in the solution (wt\%) played important in determining the sphere size of the resulting carbons. With increasing concentration of sugar from $33 \%$ to $40 \%$ and to $50 \%$, the average diameter size of the carbon microsphere increased from $5.3 \mu \mathrm{m}$ to $6.5 \mu \mathrm{m}$ and to $6.9 \mu \mathrm{m}$, respectively for carbonization time of $6 \mathrm{~h}$ and temperature of $423 \mathrm{~K}$. Such behavior also applies to the variation of the microsphere sizes with carbonization temperature and time as indicated in Table 1. Nevertheless, there is no further enlargement on the diameter size of P-CMS by lengthening carbonization time from $8 \mathrm{~h}$ to $10 \mathrm{~h}$. A plausible explanation to this point is that the solution started to turns dense enough or become saturated in which no further growth of the nuclei within the dehydrated sugar's micelle. Accordingly, the size of the carbon spherule tends to remain constant. While carbonization time does not increase the spherule size up to a certain point, the particle size of the carbon enlarges at higher carbonization temperatures and are $8.0 \mu \mathrm{m}$, $9.1 \mu \mathrm{m}$, and $9.4 \mu \mathrm{m}$ for P-CMS-50-423-8, P-CMS-50-433-8, and 
Table 1

Pore structure characteristics of samples P-CMS.

\begin{tabular}{|c|c|c|c|c|c|c|c|c|c|}
\hline Sample & Sugar/water & $t(\mathrm{~h})$ & $T(\mathrm{~K})$ & $S_{\mathrm{BET}}\left(\mathrm{m}^{2} / \mathrm{g}\right)$ & $V_{\text {mic }}{ }^{\top}\left(\mathrm{cm}^{3} / \mathrm{g}\right)$ & Average sphere size $(\mu \mathrm{m})$ & Pore Size $^{\dagger}(\mathrm{nm})$ & Yield (\%) & Purity $\left.{ }^{\ddagger} \% \mathrm{C}\right)$ \\
\hline P-CMS-50-423-6 & $1: 1$ & 6 & 423 & 128 & 0.06 & 6.9 & 0.77 & 62.2 & 52.9 \\
\hline P-CMS-40-423-6 & $2: 3$ & 6 & 423 & 126 & 0.06 & 6.5 & 0.78 & 60.3 & 53.3 \\
\hline P-CMS-33-423-6 & $1: 2$ & 6 & 423 & 123 & 0.06 & 5.3 & 0.76 & 58.4 & 52.2 \\
\hline P-CMS-50-423-8 & $1: 1$ & 8 & 423 & 127 & 0.06 & 8.0 & 0.78 & 62.7 & 55.1 \\
\hline P-CMS-50-433-6 & $1: 1$ & 6 & 433 & 129 & 0.06 & 7.8 & 0.77 & 62.5 & 54.7 \\
\hline P-CMS-50-433-8 & $1: 1$ & 8 & 433 & 130 & 0.06 & 9.1 & 0.79 & 62.8 & 57.4 \\
\hline P-CMS-50-433-10 & $1: 1$ & 10 & 433 & 133 & 0.06 & 9.2 & 0.77 & 62.6 & 57.5 \\
\hline P-CMS-50-443-8 & $1: 1$ & 8 & 443 & 136 & 0.07 & 9.4 & 0.79 & 63.1 & 58.8 \\
\hline
\end{tabular}

ब Calculated from the volume of $\mathrm{N}_{2}$ adsorbed (STP) at relative pressure 0.995 .

Determined from the $\mathrm{N}_{2}$ adsorption isotherms using the Barrett-Joyner-Halenda (BJH) model.

Measured by using an energy dispersive X-ray fluorescence (EDXRF) spectrometer.

P-CMS-50-443-8, respectively. A more detail discussion about the mechanistic aspect of the formation of carbon microspheres from sugar-subcritical water mixture and the effects of controlling parameters will be given in the next section (Section 3.3). The specific surface area of the resulting pristine CMSs in this work is fairly low (ranging from $122.47 \mathrm{~m}^{2} / \mathrm{g}$ to $135.74 \mathrm{~m}^{2} / \mathrm{g}$ ) from the perspective of porous carbon materials. This might be ascribed to the incomplete opening of pores of the carbon during the subcritical water carbonization process.

Fig. 2a displays the $\mathrm{N}_{2}$ sorption curves at $77 \mathrm{~K}$ for samples $\mathrm{P}$ CMS-50-443-8 and M-CMS-1-70, M-CMS-1.5-70, M-CMS-1.5-80, and M-CMS-2-80. It can be seen that samples P-CMS-50-443-8, M-CMS-1-70 and M-CMS-1.5-70 all display a type-I isotherm, characteristics of a microporous material. The fairly flat plateau observed in relative pressure range of $0.10-0.99$ indicates that both M-CMS-1-70 and M-CMS-1.5-70 samples contain few mesopores and therefore micropore filling was the responsible mechanism of $\mathrm{N}_{2}$ sorption. Table 2 summarizes the pore structure characteristics of the M-CMS samples. After activation treatment at a microwave irradiation level of $70 \%(630 \mathrm{~W})$ and a $\mathrm{KOH}$ to carbon ratio of $1: 1$, the specific surface area of P-CMS-50-443-8 significantly increased from $135.74 \mathrm{~m}^{2} / \mathrm{g}$ to $1350.28 \mathrm{~m}^{2} / \mathrm{g}$. This might be ascribed to the evolution of pores due to the removal of volatiles, impregnated $\mathrm{KOH}$ and its derived compounds, such as $\mathrm{K}_{2} \mathrm{O}$ and $\mathrm{K}_{2} \mathrm{CO}_{3}$ from the carbon walls during microwave irradiation. These volatiles are generated from several complex reactions during impregnation stage include decomposition, dehydration, and condensation of macromolecules. Additionally, impregnation stage also plays important for inhibiting the formation of tar during activation process [36]. It can be seen from Table 2 that the specific surface area of M-CMS increased with increasing $\mathrm{KOH}$ to carbon ratio from $988 \mathrm{~m}^{2} / \mathrm{g}$ of M-CMS-0.5-70 $(\mathrm{KOH} / \mathrm{C}$ ratio of $1: 2)$ to $1350 \mathrm{~m}^{2} / \mathrm{g}$ of M-CMS-1-70 $(\mathrm{KOH} / \mathrm{C}$ ratio of
$1: 1)$ and gradually decreased to $1248 \mathrm{~m}^{2} / \mathrm{g}$ of M-CMS-1.5-70 and $1108 \mathrm{~m}^{2} / \mathrm{g}$ of M-CMS-2-70 at higher $\mathrm{KOH} / \mathrm{C}$ ratios of 3:2 and 2:1, respectively. The micropore volume and microporous surface area have the same trend as that of the variation of the specific surface area of these samples with $\mathrm{KOH} /$ carbon ratio and microwave irradiation level. This might be attributed to the over-gasification phenomenon that leads to the shrinkage or partial collapse of the carbon framework and micropores that accounted for the high specific surface area partly swelled to mesopores or even macropores due to over burn-off. Furthermore, an excess amount of $\mathrm{KOH}$ (or metallic potassium) accelerates the catalytic gasification between the carbon surface and gaseous $\mathrm{CO}_{2}$ that intensifies carbon burn-off and diminishes its yield [37]. This explanation is also verified from the $\mathrm{N}_{2}$ sorption curves of M-CMS-1.5-80 and M-CMS-2-80 that exhibit a slightly different shape than samples M-CMS-1-70 and M-CMS-1.5-70 in which the curve plateau lies in relative pressure range of $0.10-0.99$ is visually more sloppy. This observation suggests a higher mesoporosity degree in both samples and perhaps a small percentage of macropores exists in sample M-CMS-2-80. Although some micropores are swollen to mesopores, the specific surface area of sample M-CMS-1.5-80 still relatively high and is comparable to its predecessor (M-CMS-1.5-70), indicating that the applied microwave activation conditions do not cause a severe damage to the pore structure of the carbon or excessive burn-off.

The profiles of pore size distributions of samples P-CMS and $\mathrm{M}-\mathrm{CMS}$ in Fig. $2 \mathrm{~b}$ show conformity to $\mathrm{N}_{2}$ sorption analysis. In this figure, it is clearly observed the existence of a sharp peak falls in the domain of micropores (pore width $<2 \mathrm{~nm}$ ) on P-CMS-50-443-8 sample, indicating that nanopores with a diameter size of $\sim 0.8 \mathrm{~nm}$ are evenly distributed in this carbon. Interestingly, the pore sizes between P-CMS samples are almost the same (see Table 1) and this proves that subcritical water carbonization is a suitable method for
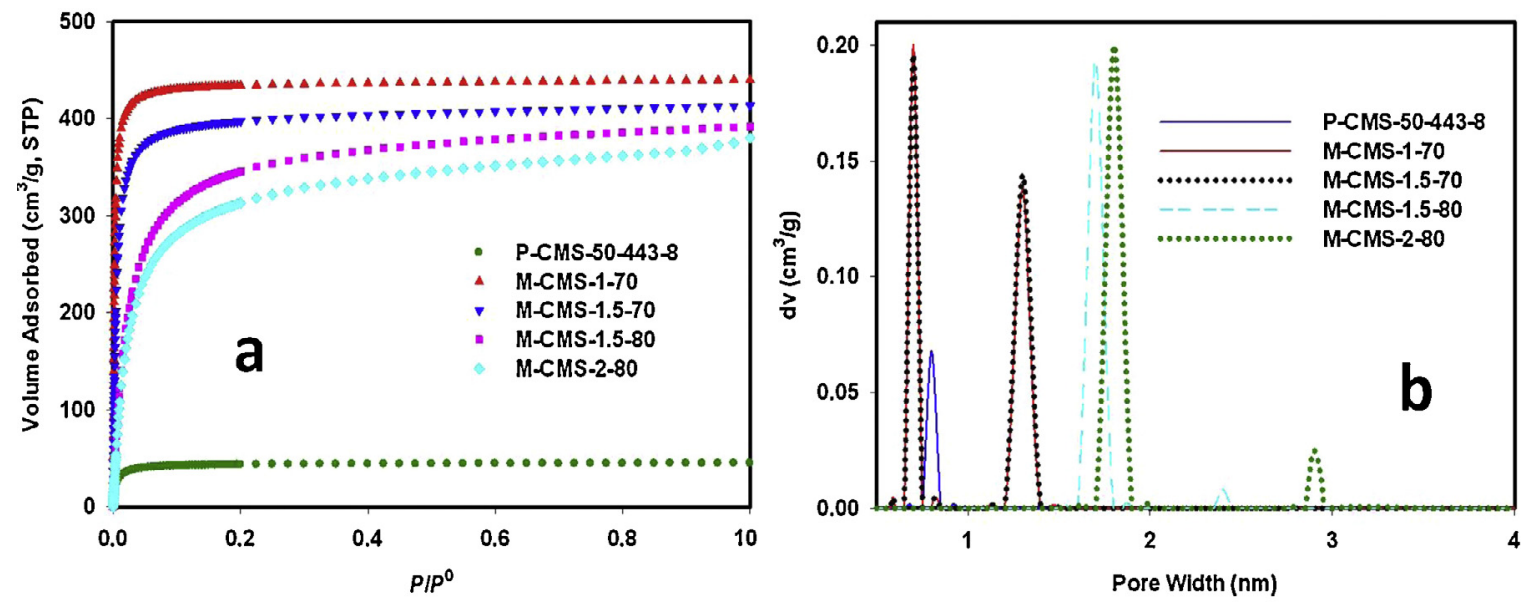

Fig. 2. $\mathrm{N}_{2}$ sorption isotherms at $77 \mathrm{~K}$ (a) and pore size distribution curves (b) of samples P-CMS-50-443-8 and M-CMS 
Table 2

Pore structure characteristics of a series of samples KOH-activated CMS.

\begin{tabular}{|c|c|c|c|c|c|c|c|}
\hline Sample & $\mathrm{KOH} / \mathrm{C}$ & \% Irradiation ${ }^{\S}$ & $S_{\text {BET }}\left(\mathrm{m}^{2} / \mathrm{g}\right)$ & $S_{\text {mic }}\left(\mathrm{m}^{2} / \mathrm{g}\right)^{\ddagger}$ & $V_{\text {mic }}\left(\mathrm{cm}^{3} / \mathrm{g}\right)^{\ddagger}$ & $V_{\mathrm{T}}\left(\mathrm{cm}^{3} / \mathrm{g}\right)^{\zeta}$ & Purity (\%C) \\
\hline M-CMS-0.5-50 & $1: 2$ & 50 & 751 & 640.98 & 0.34 & 0.47 & 75.4 \\
\hline M-CMS-0.5-60 & $1: 2$ & 60 & 844 & 737.26 & 0.38 & 0.51 & 76.1 \\
\hline M-CMS-0.5-70 & $1: 2$ & 70 & 988 & 874.14 & 0.44 & 0.56 & 76.6 \\
\hline M-CMS-0.5-80 & $1: 2$ & 80 & 1013 & 902.45 & 0.46 & 0.57 & 78.2 \\
\hline M-CMS-1-50 & $1: 1$ & 50 & 987 & 859.53 & 0.41 & 0.56 & 76.3 \\
\hline M-CMS-1-60 & $1: 1$ & 60 & 1128 & 996.40 & 0.47 & 0.62 & 77.4 \\
\hline M-CMS-1-70 & $1: 1$ & 70 & 1350 & 1216.78 & 0.54 & 0.68 & 79.0 \\
\hline M-CMS-1-80 & $1: 1$ & 80 & 1273 & 1126.55 & 0.51 & 0.67 & 79.8 \\
\hline M-CMS-1.5-50 & $3: 2$ & 50 & 953 & 820.42 & 0.42 & 0.55 & 78.7 \\
\hline M-CMS-1.5-60 & $3: 2$ & 60 & 1062 & 930.03 & 0.45 & 0.59 & 79.5 \\
\hline M-CMS-1.5-70 & $3: 2$ & 70 & 1248 & 1108.63 & 0.50 & 0.64 & 80.2 \\
\hline M-CMS-1.5-80 & $3: 2$ & 80 & 1150 & 978.60 & 0.44 & 0.61 & 82.1 \\
\hline M-CMS-2-50 & $2: 1$ & 50 & 928 & 770.98 & 0.39 & 0.54 & 79.3 \\
\hline M-CMS-2-60 & $2: 1$ & 60 & 1014 & 858.63 & 0.42 & 0.57 & 80.6 \\
\hline M-CMS-2-70 & $2: 1$ & 70 & 1108 & 943.23 & 0.46 & 0.61 & 83.0 \\
\hline M-CMS-2-80 & $2: 1$ & 80 & 1052 & 832.12 & 0.41 & 0.59 & 84.7 \\
\hline
\end{tabular}

$\S$ Irradiation levels: 50\% (450 W), 60\% (540W), 70\% (630 W), and 80\% (720W).

$\ddagger$ Interpreted by the application of micromeritics’ Dubinin-Asthakov (DA) analysis software.

$\zeta$ Calculated from the volume of $\mathrm{N}_{2}$ adsorbed (STP) at a relative pressure of 0.995

obtaining carbon microspheres with uniform nano-sized pores. In other hand, the micropores of about $\sim 0.7 \mathrm{~nm}$ (narrow micropores) and $1.2-1.5 \mathrm{~nm}$ in width appears in the M-CMS-1-70 and M-CMS1.5-70 samples. This observation supports $\mathrm{N}_{2}$ sorption results in which the pore widening phenomenon occurs during activation treatment, associated with the intercalation of potassium metals into the adjacent carbon atomic layers that responsible for the stabilization of carbon atoms in the crystallites and widening of the existing micropores [36]. Accordingly, the internal pore volume of the carbon swells after activation process, as shown in Table 2. The existence of narrow micropores may be due to the removal of volatiles and impregnated chemicals from the carbon walls. Moreover, a small percentage of mesopores with pore widths of $\sim 2.4 \mathrm{~nm}$ and $\sim 2.9 \mathrm{~nm}$ is formed in samples M-CMS-1.5-80 and M-CMS-2-80, respectively.

$\mathrm{X}$-ray diffraction is a useful technique for obtaining the detailed information about the crystal lattice and structural order of any crystalline solid, which has been extensively used for studying the carbon stacking structure. The powder diffractograms of P-CMS-50-433-8 and M-CMS-1-70 samples (Fig. 3a) show a broad diffraction peak at 2-theta angle of $24.3^{\circ}$ and $25.2^{\circ}$, respectively. This peak can be indexed to $(002)$ diffraction plane of hexagonal graphite according to JCPDS No. 75-1621 index. A weak and broad peak is also appeared in the diffraction pattern of M-CMS-1-70 at ca. $43.8^{\circ}$, which is the characteristic of ( 100$)$ $h$-graphite plane. This suggests that the resulting materials have a combination of crystalline and amorphous carbon structures where the latter has higher percentage than the former. The interlayer spacing of $\left(\begin{array}{ll}0 & 02\end{array}\right)$ graphite plane for P-CMS-50-433-8 was $0.366 \mathrm{~nm}$ while for M-CMS-1-70 was $0.353 \mathrm{~nm}$. Pimenta and colleagues confirm in their review paper that turbostratic graphite possesses an interlayer spacing larger than $0.342 \mathrm{~nm}$ [38]. Therefore, the synthesized carbons in this work can be classified as disordered graphite with turbostratically stacked layer structures. After $\mathrm{KOH}$ activation treatment, the intensity of $(002)$ peak of M-CMS-1-70 sharpen, reflecting a higher graphitic degree and crystallinity in this carbon since its interlayer spacing approaching an ideal crystalline graphite with $d_{002}$-spacing of $0.335 \mathrm{~nm}$.

The feature of Raman spectra of P-CMS-50-433-8 and M-CMS1-70 samples in Fig. 3b also shows consistency with XRD results. Two distinct peaks with strong intensity appear at frequency of about $1350 \mathrm{~cm}^{-1}$ and $1590 \mathrm{~cm}^{-1}$, which are the Raman characteristics of defect-induced band (D-band) and graphitic band (G-band), respectively. The $\mathrm{G}$-band is a Raman active mode for $\mathrm{sp}^{2}$ carbon hexagonal networks and is called as the first-order G-band while the D-band is a breathing mode of $A_{1 g}$ at the Brillouin zone (BZ) boundary K [39]. In this case, the presence of both $D$ and $G$ bands in the Raman spectra of P-CMS-50-433-8 and M-CMS-1-70 samples is a sign of imperfect graphite with turbostratic stacking arrangement. The full width at half maximum (FWHM) of the D-band in
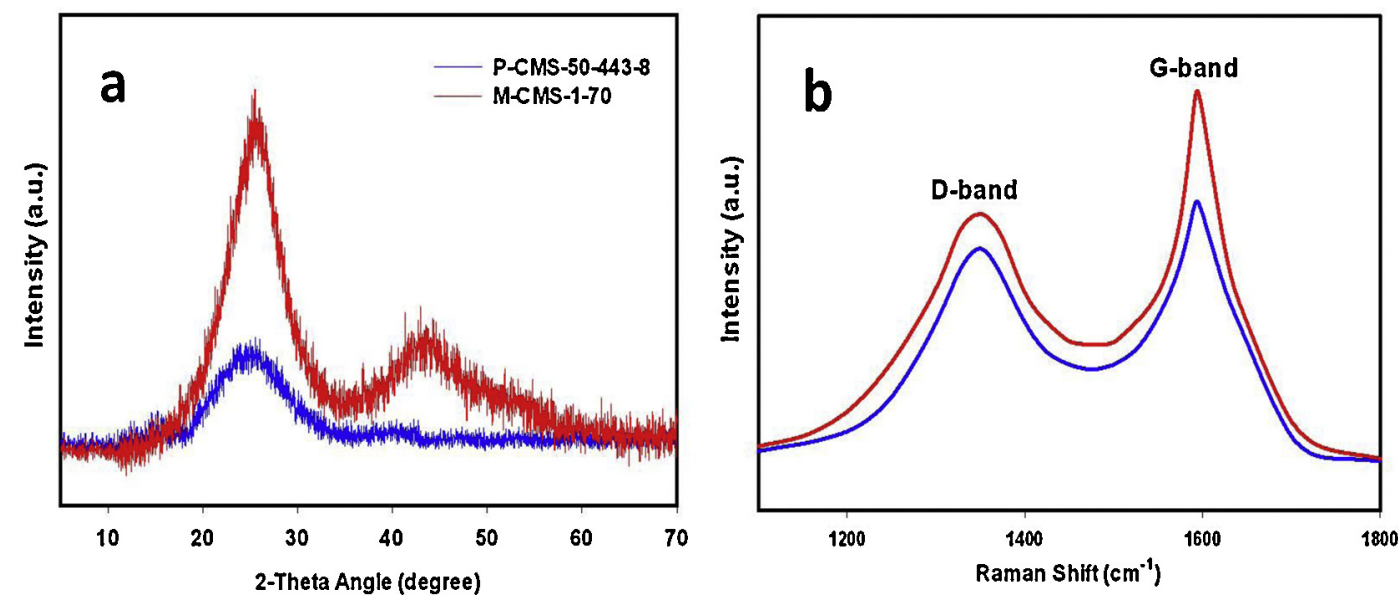

Fig. 3. XRD patterns (a) and Raman spectra measured at $\lambda_{L}=514.5 \mathrm{~nm}$ (b) of samples P-CMS-50-443-8 and M-CMS-1-70. 
Fig. 3b is visually broader than that of G-band, characterizing a fairly large proportion of structural defects and disorder in the resulting carbons. Moreover, the defects and perturbations in graphitic materials can be assessed by measuring the $D$ to $G$ peak intensity ratio [38], denoted as $I_{\mathrm{D}} / I_{\mathrm{G}}$, in which the lower the $I_{\mathrm{D}} / I_{\mathrm{G}}$ is the higher the graphitization degree is. The value of $I_{\mathrm{D}} / I_{\mathrm{G}}$ for M-CMS-1-70 is 0.71 while for P-CMS-50-433-8 is 0.84 , denoting a higher graphitization degree in the former carbon after activation treatment. The yield percentage (on the basis of carbon wt\%) of M-CMS products ranged between $75.4 \%$ and $84.7 \%$ (Table 2), considerably higher than those of pristine CMSs that ranging from $52.2 \%$ to $58.8 \%$ (Table 1 ), which agreed well with the XRD and Raman results outlined above.

\subsection{Surface functional characteristics of M-CMS and P-CMS}

FTIR technique was employed to characterize surface groups on the carbon samples before and after $\mathrm{KOH}$ activation (Fig. S1 of Supplementary data). Several absorption bands in the PCMS spectrum are positioned at wavenumbers of $3506 \mathrm{~cm}^{-1}$, $2942 \mathrm{~cm}^{-1}, 1738 \mathrm{~cm}^{-1}, 1571 \mathrm{~cm}^{-1}, 1233 \mathrm{~cm}^{-1}$, and $817 \mathrm{~cm}^{-1}$. These IR-characteristic bands are assigned to the stretching modes of $\mathrm{O}-\mathrm{H}$ bond of hydroxyl moiety, $\mathrm{C}-\mathrm{H}$ bond of aromatic skeletal, $\mathrm{C}=\mathrm{O}$ double-bond of carbonyl group in aldehydes, ketones, lactones, anhydrides, or carboxylics, $\mathrm{C}=\mathrm{C}$ double-bond within the aromatic ring, $\mathrm{C}-\mathrm{O}$ bond of phenol groups, and aromatic out-of-plane bending of $\mathrm{C}-\mathrm{H}$ bond. The aromatic $\mathrm{C}=\mathrm{C}$ and $\mathrm{C}-\mathrm{H}$ vibrational bands are the indication of the parallel graphene sheets contained in the carbon. On the other hand, the presence of oxygen functionalities in the IR spectrum of P-CMS may reflect the chemical inhomogeneity in this carbon that gave rise to the structural defects.

After microwave activation treatment, the intensities of vibrational bands related to the oxygen functionalities significantly decreased. This is likely due to the dehydration, devolatilization, and decomposition of low molecular weight compounds occurring as a result of internal and volumetric heating during microwave irradiation that responsible in the expansion of the pore structure. The stretching modes of $\mathrm{O}-\mathrm{H}, \mathrm{C}-\mathrm{O}$, and $\mathrm{C}=\mathrm{O}$ bonds gradually diminish with increasing irradiation levels from $50 \%$ to $70 \%$ and these bands visually vanish at irradiation level of $80 \%$. Moreover, the intensities of aromatic $\mathrm{C}=\mathrm{C}$ stretch and out-of-plane $\mathrm{C}-\mathrm{H}$ bending also weaken after activation treatment in comparison to the pristine carbon. These changes may be associated with the alleviation of the functional groups regarded as defects in the graphite lattice which leads to the structural rearrangement containing higher aromaticity [40].

\subsection{Mechanistic study of the formation of carbon microspheres}

In this work, the mechanistic aspect of the formation of carbon microspheres from sugar solution under subcritical water condition was investigated in order to interpret the roles of subcritical water and other experimental parameters in the reaction system. It is well-known that subcritical water possesses unique properties as it can act as an effective acid-base catalyst for assisting various reactions, unlike the liquid water at ambient condition. The acid-base catalytic properties of subcritical water are generated from the dissociation of water molecules, resulting in the formation of charged intermediate-catalysts $\left(\mathrm{H}^{+}\right.$and $\mathrm{OH}^{-}$ions). Under this condition, the dielectric constant $(\varepsilon)$ of water is progressively decreased with increasing temperatures, changing the polarity of water from highly polar to less polar or approaching that of organic solvents. Given this, the formation of carbon microspheres through subcritical water carbonization of sugar solution can be proposed to follow the free radical-catalyzed emulsion polymerization mechanism of colloidal spheres, which comprises of several stages of reaction [41].
The first stage is the dissociation of water molecules to form $\mathrm{H}^{+}$and $\mathrm{OH}^{-}$ions when the temperature of the system exceeds the boiling point of liquid water. The next stage is the protonation attack of sugar molecules through an intermolecular condensation reaction, causing the loss of water moieties. As the time advancing, the frequency of the protonation attacks becomes fiercer and the partly dehydrated sugars (in semi-fluid phase) separate out from the solution and dispersed as an aqueous emulsion. Then, a further dehydration of sugar induces the formation of nucleioligomers within the micelles in the form of tiny particles. These nuclei-oligomers gradually grow into nanoscale spherules by consuming of the micelles. The last stage is the polymerization of the grown nuclei into micron-size spherules until all dehydrated sugars in the aqueous phase are completely depleted. During the reaction, some fractions of the dehydrated sugars are transformed into simpler compounds, such as furan or 5-hydroxymethylfurfural (HMF). These sugar-derived compounds act as a co-agent for the stabilization of the colloidal spheres during the particle nucleation stage and/or they are partly condensed and polymerized to form carbon spherules.

It can be seen from Table 1 that the average diameter size of the carbon microspheres enlarges when higher concentration of sugar is used, from $5.3 \mu \mathrm{m}$ of P-CMS-33-423-6 to $6.5 \mu \mathrm{m}$ of P-CMS-40-423-6 and to $6.9 \mu \mathrm{m}$ of P-CMS-50-423-6. Similarly, the yield of the carbon increases gradually from $58.4 \%$ to $62.2 \%$ with increasing mass concentration of sugar in the solution from $33 \%$ to $50 \%$. The average size of the carbon microspheres also swells at longer dwelling time and carbonization temperature and are $8.0 \mu \mathrm{m}$ of P-CMS-50-423-8, 9.1 $\mu \mathrm{m}$ of P-CMS-50-433-8, and $9.4 \mu \mathrm{m}$ of P-CMS-50-443-8, respectively. From these results, it can be confirmed that the sugar concentration, dwelling time, and carbonization temperature all contribute positive effects toward the formation of carbon microspheres. In this context, temperature serves as an energy (heat) source to break down the hydrogen bonding of water and promote the dehydration of sugars as well the polymerization of the nuclei-oligomers to form microspheres. When carbonization time was lengthened from $8 \mathrm{~h}$ to $10 \mathrm{~h}$, the microsphere size of the carbon slightly increases from $9.1 \mu \mathrm{m}$ of P-CMS-50-433-8 to $9.2 \mu \mathrm{m}$ of P-CMS-50-433-10, denoting the saturation of the growth and polymerization of the nuclei is reached for carbonization time of $8 \mathrm{~h}$.

\subsection{Electrocapacitive properties of the P-CMS and M-CMS-based electrodes}

Cyclic voltammetry (CV) is indispensable and a standard technique used in the electrochemistry science for evaluating the performance of electrochemical devices such as supercapacitors since it provides basic knowledge directly on the capacitance behavior of the device. The CV curves of the as-prepared P-CMS and M-CMS-based electrodes within potential window from $+0 \mathrm{~V}$ to $+1 \mathrm{~V}$ at a sweep rate of $50 \mathrm{mV} / \mathrm{s}$ are depicted in Fig. 4a. It is known that a symmetrical rectangular shape of the combined curves at positive and negative sweep rates represents an ideal doublelayer capacitance behavior and quick rearrangement of the electric double-layer at the switching potentials [6]. The typical cyclic voltammograms of M-CMS-1-70, M-CMS-1.5-70, M-CMS-1.5-80, and M-CMS-2-80-based electrodes show a rapid current response on the voltage reversal at each end potential and nearly rectangular shapes, demonstrating an ideal double-layer capacitance behavior. Moreover, the curve shapes of all four M-CMS-based electrodes still present typical capacitance behavior even at a high sweep rate of ca. $50 \mathrm{mV} / \mathrm{s}$, revealing that the resulting electrodes have low equivalent series resistance and fast charge/discharge switching [6,42].

The CV profile of P-CMS-50-443-8-based electrode also shows a rectangular-like shape at the same sweep rate, representing an 

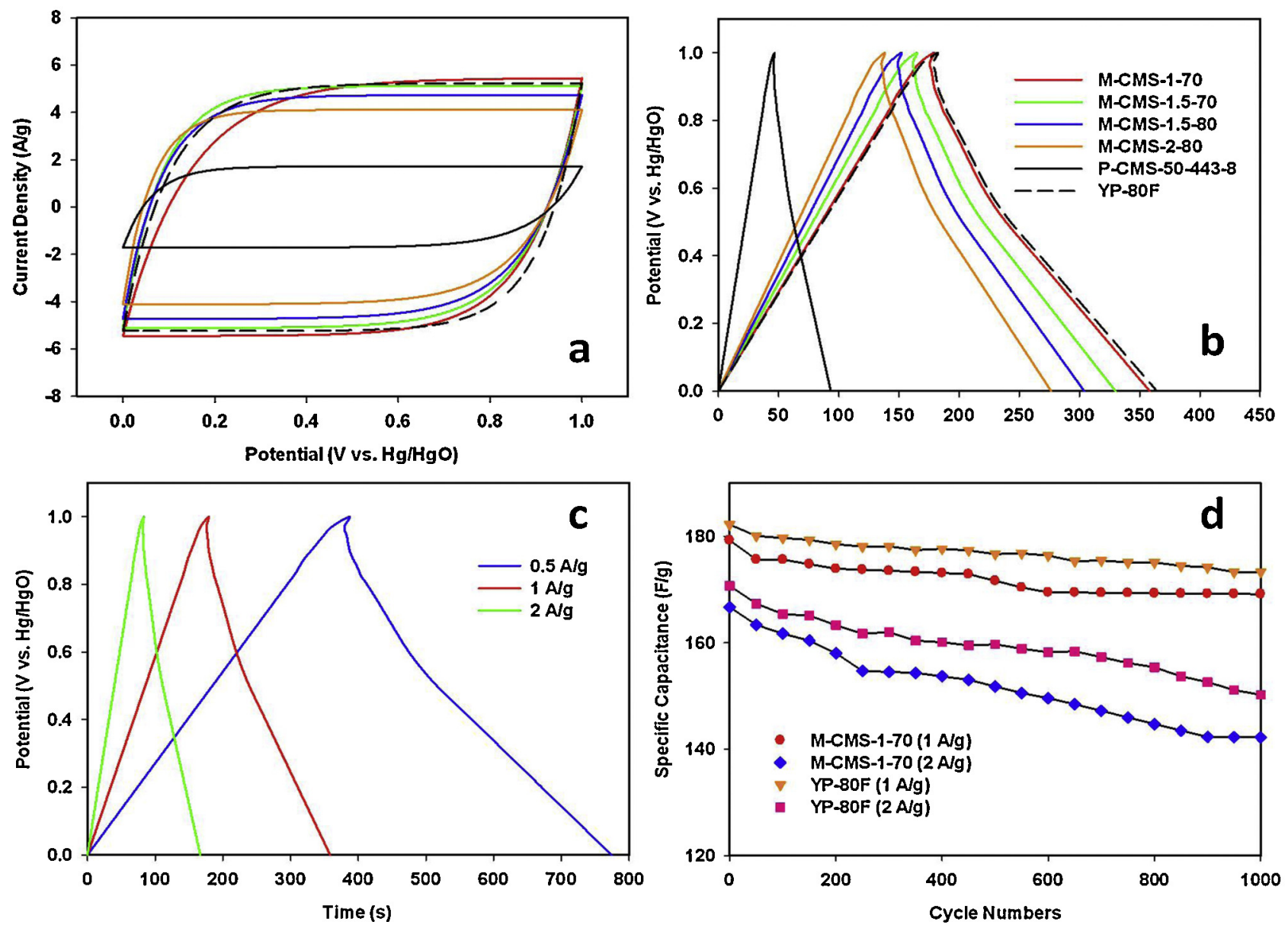

Fig. 4. Cyclic voltammetry at a sweep rate of $50 \mathrm{mV} / \mathrm{s}$ (a), galvanostatic charge-discharge curves at a current density of $1 \mathrm{~A} / \mathrm{g}$ (b), charge-discharge curves of M-CMS-1-70-based electrode at different current densities (c), and cycling performance results of M-CMS-1-70 and YP-80F-based electrodes at two current densities of $1 \mathrm{~A} / \mathrm{g}$ and $2 \mathrm{~A} / \mathrm{g}$.

ideal double-layer behavior. However, the voltammetry charge covered under the curve area is narrow, implying that this electrode has poor capacitive energy storage and is mainly attributed to its low specific surface area. In contrast to this, the area under the CV curve of M-CMS-1-70-based electrode surrounds slightly higher voltammetric charge than those under the curves of other three M-CMS samples and commercial YP-80F activated carbon and almost twice that of P-CMS-based electrode, indicating that this electrode possesses the lowest ohmic resistance and highest capacitance. When sorted from the highest to lowest on the basis of capacitance value (excluding YP-80F-based electrode) at a current density of $1 \mathrm{~A} / \mathrm{g}$ (Table 3 ), the following order is obtained: M-CMS-1-70 (179.2 F/g)>M-CMS-1.5-70 (165.0 F/g)> M-CMS$1.5-80(152.0 \mathrm{~F} / \mathrm{g})>\mathrm{M}-\mathrm{CMS}-2-80(138.3 \mathrm{~F} / \mathrm{g})$. This order confirms that the capacitance values increase proportionally with the specific surface area of the active material in the electrode. Moreover, all $\mathrm{KOH}$-activated CMS samples in this work have pore sizes larger than those of solvated electrolyte ions [43], facilitating a rapid ionic diffusion from bulk electrolyte to the inner pore structure.

The galvanostatic charge-discharge curves of the P-CMS and M-CMS-based electrodes are given in Fig. 4b. This technique is widely employed for evaluating the normalized capacitance and internal resistance of an electrochemical device and is normally coupled with CV technique. From this figure, it can be seen that the $V$ - $t$ responses of all M-CMS-based electrodes resemble symmetrical triangular shapes, which are the characteristic of an efficient double-layer capacitor with low ohmic resistance and potential drop as well as good reversibility during charging/discharging $[6,42]$. The charge/discharge time also varies at a constant current density for each M-CMS-based electrode, suggesting different specific capacitances. As shown in Fig. 4b, the electrode with M-CMS-1-70 active material exhibits the longest discharge time compared to other three M-CMS samples, likely due to higher capacitance provided by its specific surface area and good ion

Table 3

Specific capacitances of samples P-CMS and M-CMS, together with commercial activated carbon YP-80F measured at a current density of $1 \mathrm{~A} / \mathrm{g}$

\begin{tabular}{lc}
\hline Active material & Capacitance $(\mathrm{F} / \mathrm{g})$ \\
\hline P-CMS-50-443-8 & 46.7 \\
M-CMS-0.5-50 & 98.5 \\
M-CMS-0.5-60 & 110.8 \\
M-CMS-0.5-70 & 129.6 \\
M-CMS-0.5-80 & 132.8 \\
M-CMS-1-50 & 131.5 \\
M-CMS-1-60 & 150.1 \\
M-CMS-1-70 & 179.2 \\
M-CMS-1-80 & 169.0 \\
M-CMS-1.5-50 & 126.2 \\
M-CMS-1.5-60 & 140.5 \\
M-CMS-1.5-70 & 165.0 \\
M-CMS-1.5-80 & 152.0 \\
M-CMS-2-50 & 122.0 \\
M-CMS-2-60 & 133.4 \\
M-CMS-2-70 & 145.7 \\
M-CMS-2-80 & 138.3 \\
YP-80F & 182.2
\end{tabular}


transport behavior in conjunction with more appropriate pore size and well-developed interconnectivity of pores.

As tabulated in Table 3, the highest specific capacitance is held by M-CMS-1-70-based electrode $(179.2 \mathrm{~F} / \mathrm{g})$ at a current density of $1 \mathrm{~A} / \mathrm{g}$. This capacitance value is higher than those of other three $\mathrm{M}-$ CMS samples with specific capacitance of $138.3 \mathrm{~F} / \mathrm{g}, 152.0 \mathrm{~F} / \mathrm{g}$, and $165.0 \mathrm{~F} / \mathrm{g}$ for M-CMS-2-80, M-CMS-1.5-80, and M-CMS-1.5-70, respectively. However, the capacitance of the electrode fell at higher current densities, for example from $193.6 \mathrm{~F} / \mathrm{g}$ to $179.2 \mathrm{~F} / \mathrm{g}$ and $166.7 \mathrm{~F} / \mathrm{g}$ when the current density is increased from $0.5 \mathrm{~A} / \mathrm{g}$ to $1 \mathrm{~A} / \mathrm{g}$ and $2 \mathrm{~A} / \mathrm{g}$ respectively, as in the case of the M-CMS-1-70based electrode (Fig. 4c). This common phenomenon is possibly due to a potential distribution appears across the inter-electrode spacing and the increasing ohmic drop (linked to the electronic and ionic resistance) at higher current densities that restrict the double-layer charging in the inner part of the electrode, causing a capacitance loss [44]. The specific capacitance of M-CMS-1-70-based electrode is also comparable to that of YP-80F-based electrode $(179.2 \mathrm{~F} / \mathrm{g}$ vs. $182.2 \mathrm{~F} / \mathrm{g}$ ) although the latter has much higher specific surface area than the former $\left(1350 \mathrm{~m}^{2} / \mathrm{g}\right.$ vs. $\left.1948 \mathrm{~m}^{2} / \mathrm{g}\right)$. This may be related to the higher graphitization degree and more appropriate pore size and distribution of the former than the latter active material, as confirmed by several authors $[6,45,46]$.

The electrochemical stabilities of M-CMS-1-70 and YP$80 \mathrm{~F}$-based electrodes were tested by performing repetitive charge/discharge cycles at two current densities of $1 \mathrm{~A} / \mathrm{g}$ and $2 \mathrm{~A} / \mathrm{g}$, as displayed in Fig. 4d. Apparently, the capacitance of M-CMS-1-70-based electrode slightly changes from $179.2 \mathrm{~F} / \mathrm{g}$ to $169.1 \mathrm{~F} / \mathrm{g}$ after 1000 charge/discharge cycles, with more than $94 \%$ of its initial capacitance retained. The YP-80F-based electrode also exhibits excellent capacitive retention since its initial capacitance slightly declined from $182.2 \mathrm{~F} / \mathrm{g}$ to $173.3 \mathrm{~F} / \mathrm{g}$ after 1000 charging/discharging. When the current density is increased from $1 \mathrm{~A} / \mathrm{g}$ to $2 \mathrm{~A} / \mathrm{g}$, the capacitive retention of both electrodes decreases to about $85 \%$ and $88 \%$ for M-CMS-1-70 and YP-80F, respectively, likely due to greater sterical limitations. Similar observation has been recently reported by Zhang and Zhao in their work [47]. These results may reveal that the electrode prepared from M-CMS-1-70 active material has long life-cycle stability and comparable performance with commercial YP-80F activated carbon in terms of capacitive energy storage. The excellent capacitance and cycling performance of as-prepared M-CMS-1-70-based electrode might be attributed to well-interconnectivity between micropores and mesopores networks in the carbon structure, of which the former functions to store the solvated electrolyte ions by forming electric double-layer and the latter serves as a pathway for the diffusion of electrolyte ions to micropore adsorption sites. In addition, the subnanometer size of micropores of M-CMS-1-70 carbon may partly contribute to effective ion desolvation, together with highly connected mesopores, retaining high capacitance and stable electric double-layer charge/discharge over 1000 cycles.

\section{Conclusions}

Carbon microspheres with uniform nanopores of about $\sim 0.8 \mathrm{~nm}$ in diameter have been synthesized from sugar solution using the subcritical water carbonization method. This method is considered as an environmental friendly and efficient route and proven to be able to produce a relatively high carbon yield (more than 60\%) at moderate conditions without the addition of a co-monomer or a catalyst. Subcritical water serves as the dehydrating agent and the reaction medium for the conversion of sugar to carbon. It was found that the diameter of the carbon spheres is controllable by varying the concentration of sugar, carbonization temperature and time. Mechanistic study showed that the formation of carbon microspheres from a sugar solution followed a free radicalcatalyzed emulsion polymerization mechanism. Microwaveassisted $\mathrm{KOH}$ activation of the carbon spheres significantly enhanced the specific surface area, almost ten-fold higher than the pristine carbon spheres. Cyclic voltammetry and galvanostatic charge-discharge results showed that both the pristine and $\mathrm{KOH}$-activated carbon spheres exhibited an electric double-layer charge storage mechanism with a low ohmic resistance and a good reversibility. A $\mathrm{KOH}$-activated sample displayed a specific capacitance of $179.2 \mathrm{~F} / \mathrm{g}$ at a current density of $1 \mathrm{~A} / \mathrm{g}$ measured in a three-electrode cells, which is almost four times higher than that of the sample before $\mathrm{KOH}$ activation. The cycling performance results over 1000 charging/discharging confirmed that this sample has a comparable performance to that of a commercial carbon (YP-80F) in terms of both cycle life time and capacitance.

\section{Acknowledgment}

XSZ acknowledges financial support from the Australian Research Council (ARC) under the ARC Future Fellowship Program (FT100100879).

\section{Appendix A. Supplementary data}

Supplementary data associated with this article can be found, in the online version, at http://dx.doi.org/10.1016/j.electacta. 2013.07.223.

\section{References}

[1] M.D. Stoller, R.S. Ruoff, Best practice methods for determining an electrode material's performance for ultracapacitors, Energy Environ. Sci. 3 (2010) 1294

[2] J. Zhang, X.S. Zhao, On the configuration of supercapacitors for maximizing electrochemical performance, ChemSusChem 5 (2012) 818.

[3] E. Frackowiak, F. Beguin, Carbon materials for the electrochemical storage of energy in capacitors, Carbon 39 (2001) 937.

[4] T. Kyotani, Control of pore structure in carbon, Carbon 38 (2000) 269.

[5] D. Yuan, J. Chen, J. Zeng, S. Tan, Preparation of monodisperse carbon nanospheres for electrochemical capacitors, Electrochem. Commun. 10 (2008) 1067.

[6] P. Guo, Y. Gu, Z. Lei, Y. Cui, X.S. Zhao, Preparation of sucrose-based microporous carbons and their application as electrode materials for supercapacitors, Microporous Mesoporous Mater. 156 (2012) 176.

[7] M. Seredych, M. Koscinski, M. Sliwinska-Bartkowiak, T.J. Bandosz, Active pore space utilization in nanoporous carbon-based supercapacitors: effects of conductivity and pore accessibility, J. Power Sources 220 (2012) 243

[8] T.E. Rufford, D. Hulicova-Jurcakova, Z. Zhu, G.Q. Lu, Nanoporous carbon electrode from waste coffee beans for high performance supercapacitors, Electrochem. Commun. 10 (2008) 1594.

[9] J. Wang, S. Kaskel, $\mathrm{KOH}$ activation of carbon-based materials for energy storage, J. Mater. Chem. 22 (2012) 23710.

[10] A.E. Ismanto, S. Wang, F.E. Soetaredjo, S. Ismadji, Preparation of capacitor's electrode from cassava peel waste, Bioresour. Technol. 101 (2010) 3534.

[11] C. Scherdel, G. Reichenauer, Microstructure and morphology of porous carbons derived from sucrose, Carbon 47 (2009) 1102

[12] M. Armandi, B. Bonelli, F. Geobaldo, E. Garrone, Nanoporous carbon materials obtained by sucrose carbonization in the presence of $\mathrm{KOH}$, Microporous Mesoporous Mater. 132 (2010) 414.

[13] L. Wei, G. Yushin, Electrical double layer capacitors with sucrose derived carbon electrodes in ionic liquid electrolytes, J. Power Sources 196 (2011) 4072

[14] L. Li, H. Song, X. Chen, Ordered mesoporous carbons from the carbonization of sulfuric-acid-treated silica/triblock copolymer/sucrose composites, Microporous Mesoporous Mater. 94 (2006) 9.

[15] J. Bai, B. Lu, X. Bo, L. Guo, Electrochemical property and electroanalytical application of large mesoporous carbons, Electrochem. Commun. 12 (2010) 1563.

[16] C.C. Ting, H.Y. Wu, S. Vetrivel, D. Saikia, Y.C. Pan, G.T.K. Fey, H.M. Kao, A one-pot route to synthesize highly ordered mesoporous carbons and silicas through organic-inorganic self-assembly of triblock copolymer, sucrose and silica, Microporous Mesoporous Mater. 128 (2010) 1.

[17] Q. Wang, H. Li, L. Chen, X. Huang, Monodispersed hard carbon spherules with uniform nanopores, Carbon 39 (2001) 2211

[18] J. Ryu, Y.W. Suh, D.J. Suh, D.J. Ahn, Hydrothermal preparation of carbon microspheres from mono-saccharides and phenolic compounds, Carbon 48 (2010) 1990.

[19] S. Flandrois, B. Simon, Carbon materials for lithium-ion rechargeable batteries, Carbon 37 (1999) 165. 
[20] R. Alcantara, F.J. Fernandez-Madrigal, P. Lavela, J.L. Tirado, J.M. Jimenez-Mateos, C. Gomez De Salazar, R. Stoyanova, E. Zhecheva, Characterization of mesocarbon microbeads (MCMB) as active electrode material in lithium and sodium cells, Carbon 38 (2000) 1031.

[21] K. Tang, R.J. White, X. Mu, M.M. Titirici, P.A. Van Aken, J. Maier, Hollow carbon nanospheres with a high rate capability for lithium-based batteries, ChemSusChem 5 (2012) 400.

[22] K. Pan, H. Ming, Y. Liu, Z. Kang, Large scale synthesis of carbon nanospheres and their application as electrode materials for heavy metal ions detection, New J. Chem. 36 (2012) 113.

[23] J. Wu, F. Hu, X. Hu, Z. Wei, P.K. Shen, Improved kinetics of methanol oxidation on Pt/hollow carbon sphere catalysts, Electrochim. Acta 53 (2008) 8341.

[24] Y. Piao, K. An, J. Kim, T. Yu, T. Hyeon, Sea urchin shaped carbon nanostructured materials: carbon nanotubes immobilized on hollow carbon spheres, J. Mater. Chem. 16 (2006) 2984

[25] J. Zhang, Y. Zhang, S. Lian, Y. Liu, Z. Kang, S.T. Lee, Highly ordered macroporous carbon spheres and their catalytic application for methanol oxidation, J. Colloid Interface Sci. 361 (2011) 503.

[26] W. Xiong, M.X. Liu, L.H. Gan, Y.K. Lv, Y. Li, L. Yang, ZJ. Xu, Z.X. Hao, H.L. Liu, L.W. Chen, A novel synthesis of mesoporous carbon microspheres for supercapacitor electrodes, J. Power Sources 196 (2011) 10461

[27] G. Hu, D. Ma, M. Cheng, L. Liu, X. Bao, Direct synthesis of uniform hollow carbon spheres by a self-assembly template approach, Chem. Commun. 17 (2002) 1948.

[28] Z. Lei, N. Christov, L.L. Zhang, X.S. Zhao, Mesoporous carbon nanospheres with an excellent electrocapacitive performance, J. Mater. Chem. 21 (2011) 2274.

[29] L. Xu, W. Zhang, Q. Yang, Y. Ding, W. Yu, Y. Qian, A novel route to hollow and solid carbon spheres, Carbon 43 (2005) 1090

[30] V.G. Pol, M. Motiei, A. Gedanken, J. Calderon-Moreno, M. Yoshimura, Carbon spherules: synthesis, properties and mechanistic elucidation, Carbon 42 (2004) 111.

[31] H. Hou, A.K. Schaper, F. Weller, A. Greiner, Carbon nanotubes and spheres produced by modified ferrocene pyrolysis, Chem. Mater. 14 (2002) 3990.

[32] J. Liu, M. Shao, Q. Tang, X. Chen, Z. Liu, Y. Qian, A medial-reduction route to hollow carbon spheres, Carbon 41 (2003) 1682.

[33] Z. Lou, C. Chen, D. Zhao, S. Luo, Z. Li, Large-scale synthesis of carbon spheres by reduction of supercritical $\mathrm{CO}_{2}$ with metallic calcium, Chem. Phys. Lett. 421 (2006) 584
[34] Serp Ph., Feurer R., Kalck Ph, Y. Kihn, J.L. Faria, J.L. Figueiredo, A chemical vapour deposition process for the production of carbon nanospheres, Carbon 39 (2001) 621.

[35] J.M.V. Nabais, P.J.M. Carrott, M.M.L.R. Carrott, J.A. Menendez, Preparation and modification of activated carbon fibres by microwave heating, Carbon 42 (2004) 1315.

[36] A. Ahmadpour, D.D. Do, The preparation of active carbons from coal by chemical and physical activation, Carbon 34 (1996) 471

[37] J. Guo, A.C. Lua, Textural and chemical characterizations of adsorbent prepared from palm shell by potassium hydroxide impregnation at different stages, J. Colloid Interface Sci. 254 (2002) 227.

[38] M.A. Pimenta, G. Dresselhaus, M.S. Dresselhaus, L.G. Cancado, A. Jorio, R. Saito, Studying disorder in graphite-based systems by Raman spectroscopy, Phys. Chem. Chem. Phys. 9 (2007) 1276.

[39] L.G. Cancado, A. Jorio, E.H.M. Ferreira, F. Stavale, C.A. Achete, R.B. Capaz, M.V.O. Moutinho, A. Lombardo, T.S. Kulmala, A.C. Ferrari, Quantifying defects in graphene via Raman spectroscopy at different excitation energies, Nano Lett. 11 (2011) 3190.

[40] X.M. Feng, R.M. Li, Y.W. Ma, R.F. Chen, N.E. Shi, Q.L. Fan, W. Huang, Onestep electrochemical synthesis of graphene/polyaniline composite film and its applications, Adv. Funct. Mater. 21 (2011) 2989.

[41] Y. Xia, B. Gates, Y. Yin, Y. Lu, Monodispersed colloidal spheres: old materials with new applications, Adv. Mater. 12 (2000) 693

[42] H.Y. Jung, M.B. Karimi, M.G. Hahm, P.M. Ajayan, Y.J. Jung, Transparent, flexible supercapacitors from nano-engineered carbon films, Sci. Rep. 2 (2012) 773.

[43] J. Mahler, I. Persson, A study of the hydration of the alkali metal ions in aqueous solution, Inorg. Chem. 51 (2012) 425

[44] W.G. Pell, B.E. Conway, N. Marincic, Analysis of non-uniform charge/discharge and rate effects in porous carbon capacitors containing sub-optimal electrolyte concentrations, J. Electroanal. Chem. 491 (2000) 9.

[45] L.L. Zhang, T. Wei, W. Wang, X.S. Zhao, Manganese oxide-carbon composite as supercapacitor electrode materials, Microporous Mesoporous Mater. 123 (2009) 260.

[46] L.L. Zhang, X. Zhao, H. Ji, M.D. Stoller, L. Lai, S. Murali, S. Mcdonnell, B. Cleveger, R.M. Wallace, R.S. Ruoff, Nitrogen doping of graphene and its effect on quantum capacitance, and a new insight on the enhanced capacitance of N-doped carbon, Energy Environ. Sci. 5 (2012) 9618.

[47] J. Zhang, X.S. Zhao, A comparative study of electrocapacitive properties of manganese dioxide clusters dispersed on different carbons, Carbon 52 (2013) 1. 